Doubtless it is not necessary, but the obligation is the same; and a mistake into which Prof. Young has fallen is open to others.

The map which he wants - to be based on inverse wave-length or rapidity of vibration or pitch-is, I believe, in course of construction by Dr. Huggins, to whom, and not to me, is due, I think, the first idea and the proposal, Prof. Young has probably associated my name with it through a lecture delivered by my brother at Glasgow, in 1869 , in which it was advocated.

I also wish to acknowledge that I was not aware of the fact which has now been so decidedly stated, that the coronal green line is certainly practically identical in position with $1474(\mathrm{~K})$, as tested by direct comparison. Indeed, I was ignorant that such a comparison was possible, having supposed that the line in question was only visible during eclipse. I ought, of course, to have referred to Prof. Young's "Preliminary Catalogue," and probably should have done so had I been in a house instead of in a tent, a few score of miles from the nearest station. But in truth it did not occur to me that there could be any certainty about the position of a line which, as a coronal line, had never been fixed by measurement. I may now venture to ask, What guarantee was there that No. 3I of the "Preliminary Catalogue" was "the coronal line," anterior ts the Dodabetta measurement? I do not question it now, but I should like to know if the presumptive identity is supported by any characteristic difference between that line and those which are presumably due to the chromosplere. There is still a link wanting.

However, admitting the identity, and therefore the accuracy of the assigned position, we may still believe what Prof. Young says he would be glad to see proved, that "the apparent coincidence (with the iron line) is merely a very close juxtaposition." More than this : even were a very much higher dispersive power to show no resolution of the identity, should we not still be in nearly the same position as to any inference to be drawn therefrom? Evidence of physical relation between metals which present one or more lines common to both spectra may, indeed, eventually be shown (by the improbability of so frequent an accidental concurrence) to amount to proof. But this must be a prior step. To conceive it taken, and then to apply the like reasoning by analogy to the case of the single coronal line tally. ing with an iron line, seems to me speculation of the second order. Undoubtediy it would be matter for congratulation to be relieved from the liability to temptation of this kind by definite disproof. In the meantime, I camnot but regret that Prof. Young has half neutralised the good of a plain disavowal of belief in the ferrous interpretation of the coronal green line, by hazarding the query whether it may not "turn out" to be quasi-ferrous.

I am sorry - to return to the subject of nomenclature-that your respondent does not agree to my objection to " $\mathrm{D}_{3}$." Is it not plain that such a designation is haphazard? The association of idea is with $D_{1}$ due to sodium, instead of with the origin or source of the line. It tells nothing beyond the position, roughly, in the spectrum, by reference to a position which we happen to be familiar with, but with the occupant of which it has no connection otherwise. The name, in short, has no foundation in principle ; and that, I apprehend, is a lack of the first requisite in a scientific name.

The objection to Greek alphabet letters is of a different character, but not less easily answered. It is very true that, through the exertions of Prof. Young and others, "the whole Greek alphabet would not suffice to name one in three of the lines" already known; but it would nevertheless suffice (as in the somewhat analogous case of the stars) "to express as many as the memory would require to hold." There is ample precedent. The principal lines of the elements, like the principal stars of constellations, are known to some extent by Greek letters ; and as for the difficulty in respect of order, there was a time when the "lacid" stars, though very many in number, and having no very clear claims to precedence, were only known individually by personal names. Yet no sooner did a Bayer rank and name them according to apparent brilliancy, by Greek letters (to say nothing of the Roman), than the advantage of a fixed nomenclature was recognised and his work accepted; although observation must have shown that the assigned order was not always strictly correct. So would it happen now if, the lines having been lettered, further knowledge should show that the established precedence was not quite all that could be wished. The evil of slight incorrectness of this kind would be felt to be trifling compared with that which would result from an unsettling of a nomenclature established solely for convenience and involving no theory.
This would not prevent nor conflict with, neither would it render unnecessary, a far more extended tabulation depending on refrangibility. On the contrary, the want of such a classification and means of indication would be felt as soon as precise tabulation should come to be undertaken. In Kirchhoff's solar chart we have, graphically, something like what is wanted in a much more general, numerical, and tabular form-an example of a catalogue of lines. Charts are very useful, but not most handy; and they are not susceptible of such ready improvement and extension. The accumulation of results of spectroscopic research must sooner or later take the form of a catalogue of lines, from all sources, arranged in order of refrangibility; designating individuals (for special reference) where possible, according to their parent element or compound, their physical source, their cosmical habitat, or other characteristic and distinguishing indication, implied under the system of nomenclature which may be adopted; upon which would follow such details as to character (including intensity, width, definition, complexity, variability, \&c. \&c.) as present knowiedge or future research may represent as suitable material for incorporation.

So long as spectroscopic analysis is content to remain in its earliest stages - and it must be allowed to be still in its infancy, though a giant from its birth-the student and experimentalist may to a very considerable extent learn by heart or by practice such spectra as he needs; but this can never suffice for all purposes. Accumulation is continually going on, and products must be stored. Let that be once acknowledged and the task attempted, and it must follow that, no matter how rigorous and precise may be the system of tabulation, there will be not only room, not only gain, but a positive necessity for an intelligible use of that kind of descriptive indication which is only to be found in scientific classification and nomenclature.

A general catalogue such as I contemplate would command, if compiled with even moderate knowledye and care, a very general acceptance. Unquestionably it would be extended, modified, improved upon, by subsequent work; but, so far as nomenclature is concerned, it would probably undergo but slight alteration - the less the better. It would form a basis on which any number of special catalogues might rest, without interfering with its permanence as a calalogue of reference.

I do not pretend to say that the task is a simple one; quite the reverse. Dut, then, all the more honour to vinoevar accomplishes it

Bangalore, July 29 J. HERSCHEL

\section{Jeremiah Horrox}

I OBSERVED in a number of NATURE some three weeks ago an inquiry relative to $\mathrm{J}$. Horrox, the astronomer. My wife is descended from Horrox, and I knew that one of her friends had his life, but have not been able to find it till now. The book has just been sent to me here.

The Rev. Jeremiah Horrox was born in Toxteth Park, near Liverpool, in 1619 , and died in 1641 , aged 22 :

The life is by the Rev. A. B. Whatton, published by Wertheim, Macintosh, and Hunt, 24, Paternoster Row, 1859, and includes a translation of his discourse on the Transit of Venus.

HENRY HOLIBAY

Muncaster Castle, Ravenglass, Carnforth, Sept. 20

\section{Millions of Millions}

WIry do not Messrs. Ranyard and Co. adopt the late Benjamin Gompertz's most convenient notation of prefixing a circle to the first significant figure, or suffixing a circle to the last significant figure having therein a digit for the number of zeros employed?
Thus :
(5) 718 is 00000718

And 718 (b) is 718000000

74, Offord Road, N., Sept. $x$

\section{S. M. DRACH}

\section{Analogy of Colour and Music}

IN Nature, No. 150, p. 393, a letter from Mr. G. C. Thompson is headed "Correlation of Colour and Music." As this Jetter refers to a paper of mine published some time ago, permit me just to say that Mr. Justice Grove has in your journal objected to the use of the word "correlation" employed in this sense. Entirely coinciding with the opinion of the eminent parent of this 